Village, Andrew ORCID:

https://orcid.org/0000-0002-2174-8822, Powell, Ruth and Pepper, Miriam (2016) Bonding and bridging among first generation Asian migrants in Australian Protestant churches. Journal of Ethnic and Migration Studies, 43 (11). pp. 1943-1963.

Downloaded from: http://ray.yorksj.ac.uk/id/eprint/1747/

The version presented here may differ from the published version or version of record. If you intend to cite from the work you are advised to consult the publisher's version: http://www.tandfonline.com/doi/full/10.1080/1369183X.2016.1240027

Research at York St John (RaY) is an institutional repository. It supports the principles of open access by making the research outputs of the University available in digital form. Copyright of the items stored in RaY reside with the authors and/or other copyright owners. Users may access full text items free of charge, and may download a copy for private study or non-commercial research. For further reuse terms, see licence terms governing individual outputs. Institutional Repository Policy Statement

\title{
RaY
}

Research at the University of York St John

For more information please contact RaY at ray@yorks.ac.uk 


\section{Bonding and bridging among first generation Asian migrants in Australian Protestant churches}

\section{Andrew Village}

Theology and Religious Studies, York St John University, York, UK.

\section{Ruth Powell}

Miriam Pepper

NCLS Research, Australian Catholic University, North Sydney, Australia

Correspondence to

Professor Andrew Village, York St John University,

Lord Mayor's Walk,

York, YO31 7EX, UK.

Tel: +44 (0)1904 876723

E-mail: a.village@yorksj.ac.uk

Acknowledgements and Funding

The National Church Life Survey is a project of NCLS Research, a collaboration of four primary sponsors (Anglicare Sydney Diocese, Uniting Church Synod of NSW and ACT, Australian Catholic Bishops Conference, and the Australian Catholic University) in partnership with Australian churches. We thank the thousands of denominational and local church leaders as well as the hundreds of thousands of church attenders for their long-term participation.

Word count:

Main text (excluding tables) plus references: 8777

Main text (including tables) plus references: 9933 


\section{Bonding and Bridging among first generation Asian migrants in Australian Protestant churches}

Around a third of Asian migrants to Australia self-identify as Christians, and many join churches where they meet fellow migrants and other Australians. Churches might thus be places that can foster the integration of Asian migrants into Australian society. This paper uses social network and social capital theory to examine the prevalence of bonding and bridging among 61,386 churchgoers from 2,135 Protestant churches who completed the Australian National Church Life Survey in 2011. We compared levels of bonding and bridging social ties of first generation Asian migrants (FMAG) with Australians born of Australian-born parents (ABOAP). FGAM joining congregations had fewer social ties than ABOAP, and developed bridging (but not bonding) more slowly. FGAM had lower bonding but higher bridging in MonoAnglo congregations compared with Multicultural or MonoAsian congregations. The results suggest that FGAM who are in MonoAnglo churches may be less tightly bound to their congregation, but more likely to bridge beyond it, than are FGAM in multicultural or largely Asian congregations.

Keywords: ethnicity, homophily, religion, social capital, social networks 


\section{Introduction}

Australia is a country shaped by migration. The proportion of the population born overseas was less than 10\% in 1951 but rose to 28\% in 2014 (ABS 2014). Although people born in the UK form the largest group of migrants (5-6\% of the population), the fastest growing groups are from Asia. Between 2004 and 2014 the proportion of the population born in the UK fell from $5.6 \%$ to $5.2 \%$, while the proportion born in China rose from $1.0 \%$ to $1.9 \%$ and the proportion born in India rose from $0.7 \%$ to $1.7 \%$. Net overseas migration (total immigration minus emigration) peaked in 2008 at nearly 300,000, but fell to 212,700 in 2014. (ABS 2012).

The integration of migrants into the country remains an important cultural and political issue in Australia. At one level it refers to integration at the political or institutional level, but the more direct effects for immigrants themselves are related to economic and social domains (Collins 2013). Economic issues are concerned with how successfully migrants are able to join and thrive in the workforce, while social issues concern settlement patterns, social cohesion and national identity. Despite local variations and some widely reported incidents (the 2005 Cronulla beach riots are often cited as an example) most migrants settle into Australian society successfully (Collins 2013, Clyne and Jupp 2011, Bouma, Ling, and Pratt 2014). This does not mean that ethnic minorities always find it easy, and Collins (2013, p.146) argues that 'Racist attitudes and racial discrimination persist.'

In these circumstances it is hardly surprising that social scientists continue to examine the factors that foster the integration or assimilation of migrants. A number of writers have used the concepts of social ties (Liu 2013, Moroşanu 2016, Ryan 2011) and social capital (Allen 2010, Cederberg 2012, Missingham, Dibden, and Cocklin 2006, Jacobs and Tillie 2004, Lancee 2012, 2010) to explain differences between individuals or communities in the settlement experience of migrants. The two concepts are closely linked because social capital is thought to accrue through interactions between people who share social ties. Social capital is notoriously difficult to define (Bjørnskov and Sønderskov 2013), but most writers refer to it as resources generated by social networks of reciprocity and trust that arise from interpersonal relationships (Field 2008, Portes 1998, Baker and Miles-Watson 2010, Esser 2008). It is through participation in social networks that migrants are assumed to form ties that create opportunities for economic and social advancement in their new homeland (Carrington and Marshall 2008, Missingham, Dibden, and Cocklin 2006, Jacobs and Tillie 2004, Cederberg 2012, Granberry 2014). Churches and other religious institutions are 
thought to be places that generate social capital (Putnam 2000, Allen 2010, Andrews 2011, Schwadel 2005, Smidt et al. 2003, Weller 2005) and can be important social organisations for first-generation migrants (Peschke 2009, Watson 2009, Allen 2010, Cheong et al. 2007, Foner and Alba 2008, Foroutan 2008).

This paper draws on data from the 2011 National Church Life Survey (NCLS) to compare social ties among first-generation Asian migrants (FGAM) attending Protestant churches in Australia with that among a 'control' group of Australians born of Australian parents (ABOAP). The underlying question is whether migrants are helped to develop social networks beyond a congregation by belonging to a congregation. In order to answer this it is first necessary to define the notion of bonding and bridging ties used in this study and show how it might be both a positive and a negative force for social integration among migrants. Context is important in defining any role of social networking in migrant inclusion, so we will next briefly explain the history and nature of Asian migration into Australia and the particular context of migrants in this study. The next step is to outline the individual and congregational-level factors that might influence levels of social networking. Of particular interest here is how the level of social networking is related to the length of time someone has been attending their church (termed ‘duration' here), and the degree of cultural homogeneity in congregations. We will then use multi-level models to examine simultaneously the effects on social ties of individual and contextual-level predictors and their interaction.

\section{Bonding and bridging}

Of the many different conceptualisations around the idea of social capital, Robert Putnam's distinction between bonding and bridging has been particularly influential (Putnam 2000). Bonding and bridging terminology in social capital theory is analogous to the notion of strong and weak ties that derive from network theory (Granovetter 1983, 1973). Bonding social capital is generated between people within the same organisation or social group, and Putnam refers to it famously as 'a kind of sociological superglue' (2000, 23), generating 'thick trust' through sustained interaction with particular people (Putnam, Leonardi, and Nonetti 1994, 171). Bridging social capital is generated between different organisations or social groups. Putnam $(2000,23)$ referred to this as 'WD-40', a lubricant rather than a glue, emphasising that it adheres to networks that exist across heterogeneous social groups and which bring people into contact with those who are different from themselves and who they may not know very well. Bridging social capital associated with 'thin' trust of others through more fleeting interactions with a range of heterogeneous groups, which might nonetheless offer more 
opportunities for social or economic advancement. This was the notion suggested by Granovetter (1983), who pointed out that 'weak' social ties beyond the close-knit family or ethnic group might be more helpful in allowing people to access the resources associated with social capital. Putnam draws on Briggs (1997) to argue that bonding helps individuals to 'get by' (i.e., it offers social support) whereas bridging helps individuals to 'get ahead' (i.e., it offers opportunities to access external assets).

The relationship between social ties and social capital has been debated for many years, partly because social ties may be necessary, but not necessarily sufficient, for the generation of social capital (Lin 1999, Snijders 1999). Social ties are relationships that might generate social capital, but whether they actually do may vary from one context to another. The complexity of how exactly how migrants generate social capital, and the nature of that capital, is being revealed by detailed qualitative studies of small groups of migrants (see, for example, Ryan 2011, Moroşanu 2016, Iosifides et al. 2007, Svendsen 2006). This quantitative study uses proxy measures of bonding and bridging social ties to investigate how they vary between migrants and non-migrants in a large sample of church congregations.

\section{Social ties, migrants, and religion}

When applied to the study of migrants, bonding and bridging ties may have different effects, depending on the nature of the networks being studied (Foner and Alba 2008, Allen 2010), and the political, economic or cultural structure in which migrant communities are located (Cheong et al. 2007, Connor and Koenig 2013). New migrants will often tend to settle where there are other people of the same family, ethnicity or nationality. In these circumstances, the tendency can be to develop ties within the migrant community, but not necessarily outside it (Granberry 2014, Noguera, Herzog, and Fleerackers 2013).

Where religion is a central facet of migrant identity, religious organisations may function as key loci for creating the networks that generate social capital. Churches may foster bridging by organising contacts with other groups, empowering individuals to volunteer in the community, or increasing their political activism (Smidt 2003). For migrants, religious institutions may connect them to new culture and traditions, directly provide resources (such as language lessons or counselling), or allow them to access other resources by diversify and strengthen their external social networks (Allen 2010, Greeley 1997, Ley 2008).

Where migrants form homogenous congregations the assumption has often been that this will reduce the chances of social integration beyond the migrant group leading to 
bonding rather than bridging capital. This idea has been prevalent in sociology since pioneering studies of Christian or Jewish migrants in the USA (Handlin 1951, Herberg 1955, Gordon 1964) and more recently has been applied to Muslim migration in various parts of the world (Maliepaard and Phalet 2012, Allen 2010). Where religion and ethnic or national identity are closely intertwined there can be strong segregation between migrants and natives, which is fostered by religion creating what has been termed 'bright boundaries' between these groups (Alba 2005). However, religious institutions can also be organisations that enhance integration and cohesion, either because they have a more open attitude to social engagement beyond the congregation, or because migrants share the same religion as natives, and gravitate to largely native congregations. In the latter circumstance, migrants who develop church-based ties are likely to be networking with non-migrants in the same congregations. In this context, bonding ties are, to some extent, the same as bridging ties.

Empirical evidence of the relationship of religion, social capital and social integration among migrants is mixed, reflecting the differences between native and migrant religious cultures in different parts of the world. For example, Foner and Alba (2008) suggest that the different role that religion plays for immigrant inclusion in the USA and Europe is related to the background of the religious immigrants, the religiosity of the native population, and historically conditioned relationships between state and religious groups. In the USA religion has largely been seen as a positive force, and successive waves of migrants of different religions have been able to foster their religion and religious identity alongside civic participation and American identity. In Europe, where religion is generally less prevalent and there is often a contrast between a largely Christian native culture and a largely Muslim migrant culture, the integration has often been more troubled. Richard Alba (2005) makes a similar point in discussing the role of religion in blurring or sharpening ethnic boundaries. He suggests Mexican migrants into the USA encounter ethnic boundaries that are blurred by the existence of a Catholic faith that is shared with many natives. In Europe, however, North African Muslims arriving in France or Turkish Muslims arriving in Germany encounter bright boundaries made more so by the discontinuity of secular and religious cultures.

Given the complexity of the migrant-native interactions, the role of social networks in fostering social cohesion may be multifaceted and complex. Cheong et al. (2007) argue that the simple identification of bonding capital as 'bad' and bridging capital as 'good' needs to be nuanced and challenged. This would seem to be especially so where migrants share the same religion as natives, so that religious institutions may be a positive force for social cohesion and the integration of migrants (Peschke 2009, Weller 2005). In Australia, Protestant and 
Catholic Christianity have been the main forms of religious expression, so Christian migrants have the opportunity to join institutions where the dominant culture is related to that of longstanding Australians. Networks within congregations offer opportunities for migrants to create social ties by bonding with those born in Australia, though they may find it easier to bond if they are in congregations that consist mainly of migrants from their own ethnic background. In addition, migrants could develop bridging ties either by joining church-based, outward-facing activity groups, or by being introduced to external networks through friends they make at church.

When someone starts to attend a particular church they will already belong to other social networks. Migrants may have fewer of these, especially if they have only recently arrived from another country. Bonding ties with the congregation will develop over time, and may help to create new bridging ties if fellow congregants have access to other, external networks. We have used differences in duration in the church to test ideas about the development of the two types of social ties over time, on the assumption that difference between individuals of different durations reflects the likely average pattern of development among individuals. This may not be so if the strength of ties affects leaving, so that only those individuals with high initial bonding stay for long in a church. While this may be so, it is equally likely that social ties develop over time, and this is our assumption when interpreting the effect of duration.

\section{Homophily and social networking}

Homophily describes the widely observed phenomenon that people generally tend to associate with people who are similar to them in terms of social location and experience (Lazersfeld and Merton 1954). This tendency has been seen as reducing the likelihood of assimilation by decreasing the desire to mix beyond one's own social network (McPherson, Smith-Lovin, and Cook 2001). Studies of homophily and congregations (mainly from the USA) suggest that most, but not all, congregations are strongly homogenous with respect to the social background, ethnicity and beliefs of their members (Emerson and Smith 2000, Dougherty 2003).

Putnam's definition of bonding social capital assumed that it would be between homogeneous groups, and he specifically mentioned 'ethnic enclaves' in this respect. In contrast, he suggested that bridging capital is generated by networking with people 'across diverse social cleavages' (Putnam 2000, 22). If homophily operates in congregations according to native or migrant status, the strength of social ties may depend not only on an 
individual's status, but also on the make-up of their congregation. In Australia, Christian migrants from Asia may be able to generate more bonding ties if they are in congregations that have a large proportion of others who are also Asian migrants. Bonding ties generated within mixed congregations may also contain an element of bridging ties if they foster networks between members who are culturally and ethnically diverse. Bridging beyond congregations may be fostered if FGAM mix with ABOAP, who may offer them access to networks that reach beyond the church. If this is the case, congregations where there is a higher proportion of ABOAP may offer FGAM more opportunities for generating bridging ties.

\section{Asian migration to Australia}

Asian migration to Australia began in the nineteenth century as European settlers looked for cheap sources of labour to run gold mines in Victoria and New South Wales and sugar cane farms in Queensland (Jayasuriya and Kee 1999). Concerns over the extent of this influx led to the notorious 'White Australia' policy, enforced by legislation passed in the first decade of the twentieth century, which continued to exert influence until the 1960s. From the 1960s there was a growing liberalisation of immigration laws that that sought to remove any discrimination on the grounds of race, colour or national identity, driven notably by the Whitlam government which rescinded the 'White Australia' policy in 1973 and then passed the 1975 Racial Discrimination Act which made the use of racial criteria unlawful for official purposes.

The changes since the 1970s have seen a move towards multiculturalism (Clyne and Jupp 2011, Bouma 1995, Bouma, Ling, and Pratt 2014), but one which has its critics and which has met with some resistance (Jupp 1995, 2009, Ang 2003). In 1995 James Jupp wrote:

Australia is no longer an isolated British outpost nor is it still wedded to the idea of White Australia based on fear of Asia. Officially Australia is a multicultural society, an active participant in the economics and politics of the Asia-Pacific region, and a fully independent state on the verge of severing its remaining constitutional links with the United Kingdom. (p. 223)

The picture of Australia being more closely integrated with Asia is reflected in the changing patterns of Asian migration. Figures for the top ten source countries for settler arrivals (Jayasuriya and Kee 1999, 27) show that in the 1960s these were overwhelmingly from the UK and Ireland, with no Asian countries in the list. The first Asian country to appear was Malaysia in the 1970s. By the 1990s five of the top ten countries were Asian, with China 
having the same number of settlers as the UK. Since then the trend has continued, with figures for 2012/13 indicating that half of the approximately 152,000 settlers were from Asia, which accounted for six of the top ten source countries (in descending order): China, Philippines, Malaysia, Vietnam, Sri Lanka (DIBP 2015).

\section{Protestant congregations in Australia}

The religious culture of Australia has historically been dominated by the settlement of Europeans from Protestant and Catholic backgrounds. For this study we have selected worshippers at Protestant churches because Catholic migrants may behave differently. Religious affiliation has declined generally in Australia in recent decades (see table 12 in DIBP 2014), but even in the 2011 census, 61\% of Australians self-identified as Christian, with $41 \%$ of these identifying specifically as Catholic, 28\% as Anglican, and 21\% as other Protestants. In that census there were around 1.7 million residents born in Asia, of which 34\% identified as Christian. Among these Asian Christian migrants, around 62\% were Catholic, 8\% Anglican, and 27\% other Protestant denominations such as Baptist, Presbyterian, Uniting Church, and Pentecostal (ABS 2015). Although most Asian migrants may be either nonreligious or affiliated with non-Christian religions, over a third seem to have Christian roots, and may therefore be likely to join Christian churches when they settle in the country. Christian churches may thus have an important role in helping them to integrate into Australian society, and to foster more generally the inclusion of Asian migrants.

With regard to ethnic makeup, Australian congregations can be categorised by ethnic make-up into 'monocultural AngloCeltic', ‘monocultural non-English-speaking (NES)', and 'multicultural'. A congregation can be considered multicultural when $20 \%$ or more of its members have a cultural background that is different from the dominant cultural group. Research suggests that this threshold represents a 'critical mass' at which the presence of minority groups is likely to permeate an organisation such as a congregation (Emerson and Kim 2003). There are no national figures on the number of monocultural NES congregations in Australia, but the 2011 NCLS included a question on relationships with NES congregations (Duncum, Hancock, and Powell 2014). Just over a fifth (21\%) of sampled churches had some relationship with a NES congregation, either because they shared a church building (9\%), shared worship with special NES groups (2\%), had separate worship but shared small groups (6\%), or had some other arrangement (4\%). In this study we have categorised congregations according to the ethnicity of congregants. The majority of churches in this study were monocultural AngloCeltic congregations where English was the common 
language and there was some possibility of migrant minorities forming networks with nonmigrants through their church activity. A small minority were classed as monocultural Asian congregations, which were likely to be NES. Also included are multicultural congregations where the services were likely to be in English but there was a significant proportion of ethnic Asians.

\section{Research questions}

Although some theory suggests developing bonding capital may detract from developing bridging capital in some denominations (Beyerlein and Hipp 2006, Wilson and Janoski 1995), previous studies of Australian churches suggests the opposite maybe true (Leonard and Bellamy 2010). Work with immigrant and multi-ethnic churches suggests migrants can develop networks in the wider community through the contacts that they make within their congregation (Allen 2010, Ley 2008). We suggest that involvement in congregations over a number of years leads to increased bonding ties, and this is also true for bridging ties because networking in a congregation opens opportunities for networking beyond it. If intracongregational bonding promotes rather than reduces bridging ties we predict that:

H1.1: Levels of bonding and bridging are positively correlated at both individual and congregational level.

Leonard and Bellamy also showed that the level of bridging capital relative to bonding capital was higher among those from English-speaking backgrounds. This might be because nonmigrants have more social networks generally, and are less reliant on congregations to develop bridging ties. This leads to the following hypothesis:

H1.2: FGAM have lower levels of bridging ties, relative to bonding ties, compared with ABOAP.

Bonding is likely to be lowest when people first arrive in a congregation, and to increase over time as they get to know others and join groups. On average, migrants and non-migrants should both start from similar levels of bonding; unless one group is more likely than the other to already know people in the congregation when they join (and there is no evidence to suggest whether this is likely or not). Unless they have been in the country for a long time, first generation migrants are likely to have fewer bridging ties than those who were born in the country. Being part of a congregation could increase bridging ties more for migrants than for others, so that the disparity in bridging ties between migrants and non-migrants will be 
lowest among the most long-standing members of congregations. This suggests two hypotheses related to social ties and duration:

H2.1: For those who have just joined a congregation, FGAM will have similar levels of bonding ties, but lower levels of bridging ties, compared to ABOAP.

H2.2: Once they join a congregation, FGAM develop bonding ties at the same rate as ABOAP, but they develop bridging ties more rapidly because they benefit more from congregational networks for developing such ties.

Homophily suggests that the level and development of bonding ties will depend on the interaction of individual migrant status and their predominant congregational culture. If so:

H3.1: FGAM in MonoAsian or Multicultural congregations will have more bonding ties than those in MonoAnglo congregations.

Bridging ties should be less influenced by homophily, but migrants in MonoAnglo congregations may have better access to bridging networks through meeting non-migrant fellow congregants. Therefore:

H3.2 FGAM in MonoAnglo congregations will have more bridging ties than those in other congregations.

\section{Method}

\section{Sample}

The NCLS, which is a local church-based survey, has collected data from thousands of churches and hundreds of thousands of congregants from approximately 20 Christian denominations across Australia every five years since 1991 (Pepper, Sterland, and Powell 2015). The 2011 National Church Life Survey was conducted from September to December and involved over 3,000 local churches from 23 denominations. 'Local church' refers to a particular address, where there may be serval worship services and returns from different services were aggregated to calculate 'congregational-level' variables. There were around 260,000 adult participants who completed surveys in one of eight languages: English, Chinese, Vietnamese, Korean, Tongan, Italian, Arabic and Dinka (NCLS 2013). This study is based on the main survey instrument given to Protestant churches and completed by attendees 
at worship services. A sub-sample was used which excluded teenagers and those aged over 79 as the latter in particular may be constrained in forming networks because of age-related decreased mobility. Also excluded were churches that had 10 or less responses, churches that failed to return sufficient numbers of survey forms to meet sample adequacy criteria (based on standard error calculations and finite population corrections), and one outlier that had 1500 (the next largest church returned 742 replies), leaving a final sample of 2135 churches.

The questionnaire included two items used to identify FGAM and ABOAP:

1. Where were you born? was a forced-choice question with 18 possible replies including 'Australia', 'Korea', 'China/Hong Kong', 'Vietnam', 'Philippines', 'India/Sri Lanka' and 'Other Asia'.

2. Where were your father and mother born? had three possible answers for each parent, 'Australia', 'Another country where English is the main language', and 'Another country (where English is not the main language)'.

There was no direct question about migrant status, but from these questions we identified two contrasting groups for the purposes of this study: ABOAP were those born in Australia of Australian-born parents; FGAM were those born in Asia with neither parent born in Australia. Excluded from the dataset were migrants from outside Asia and second-generation migrants: the focus of the paper is on Asian migrants, and it was not possible to ascertain the origins of those born in Australia of non-Australian-born parents.

Of the 112,846 participants aged 20-79 from this sub-sample of Protestant churches, 64,544 were either ABOAP or FGAM, of which 61,386 had complete data for all variables used in this analysis. The final sample comprised 7,872 (12.8\%) FGAM, the majority of which (88.2\%) had parents who were born in a country where English was not the main language. The countries of origin of the Asian migrants were: China/Hong Kong (37.1\%), India/Sri Lanka (15.8\%), Philippines (9.0\%), Korea (5.8\%), and Vietnam (2.1\%), with other, unspecified, countries accounting for 31.3\%.

Compared with ABOAP, Asian migrants were more likely to be male, younger, never married, have degrees, and to be employed (Table 1). They were also more likely to attend church on a weekly rather than a less frequent basis. Unsurprisingly they had lower duration in the congregation than ABOAP: over half had been coming to their congregation for less than six years, compared with just under a third of ABOAP.

[Table 1 about here] 


\section{Dependent variables}

NCL surveys have usually included a range of items that relate to bonding and bridging social ties and which have enabled studies of social capital as a resource of the collective community (Leonard and Bellamy 2015, 2006, 2010, Robbins, Francis, and Powell 2012). The 2001 NCLS data were used by Leonard and Bellamy (2010) to create a bonding social capital index based on twelve items that included frequency of attendance and duration (number of years involved with the current congregation). Our study looks at how social ties vary in relation to attendance and duration, so it was necessary to develop measures of bonding and bridging that excluded these variables.

Bonding ties were assessed using responses to items asking about involvement in congregational activity ( 0 = none; 1 = one type; 2 = two types); sense of belonging to congregation $(0=$ not strong; $1=$ strong but reducing; $2=$ strong $)$ or denomination $(0=$ not strong; 1 = neutral; 2 = strong); ease of making friends ( 0 = not easy; 1 = neutral; 2 = strong); financial commitment to the congregation ( $0=$ irregular; $1=<5 \%$ of net income; $2=>5 \%$ of net income); number of roles in the congregation $(0=$ none; $1=$ one role; $2=$ two or more roles); and if they agreed that the leadership encouraged respondents to use their gifts and skills ( 0 = disagree; 1 = neutral; 2 = agree). These were considered to be a proxy measure of the strength of an individual's networking relationships within the congregational context.

Bridging ties were assessed by three multiple-response items, with the number of responses summed to give an overall score. The first asked about outward-facing congregational activities, and offered two possible responses. The second asked about involvement in groups that were not connected to the congregations, and offered five response that included community service, social action, sports, and youth groups. The third asked about various activities in the last twelve months and included such things as lending money to someone outside the family and contacting a parliamentarian or local counsellor. Although activities related to congregation members were not specifically excluded, the focus of the question was taken to be bridging rather than bonding.

\section{Predictor variables}

Migrant status was coded as $1=$ FGAM and $2=$ ABOAP.

Congregational culture was measured from data aggregated at church level on the full survey data using the item 'Where were you born?' The proportion of 'AngloCeltic' in a congregation was taken as the sum percentage of those born in Australia, New Zealand, UK, Ireland, and North America. 'MonoAnglo' congregations were those where this proportion was greater 
than $80 \%$. 'MonoAsian' congregations were those where the percentage born in Asian was over 60\% (a lower threshold was used, to allow for second generation Asian migrants). The remaining congregations were classified as 'Multicultural'. There were 16 congregations that had more than 60\% from a non-Anglo migrant group besides Asian, and these were excluded. For regression analyses, we used MonoAnglo status as a dummy variable to compare people in these congregations with those in Multicultural or MonoAsian congregations.

Church attendance was measured on an ordinal scale and treated as a continuous co-variate $(1=<$ monthly, $2=$ monthly, $3=2-3$ times a month, $4=$ weekly, $5=>$ weekly $)$.

Duration was the number of years participants had been going to services or activities at their congregation, recorded on a six-point ordinal scale and treated as a categorical variable in order to calculate marginal means. Those who were visiting were excluded from the sample.

\section{Control variables}

Individual-level control variables were sex ( 1 = female, 2 = male), age (by decade), marital status (coded into dummy variables 'never married', 'married', 'divorced/separated'), education level (coded into dummy variables 'school' and 'degree'), employment status (coded into a dummy variable 'employed').

Congregational-level control variables were size (aggregated from the total number of returns from each church in the full survey) and church tradition (based on denomination with $1=$ 'Other Protestant', 2 = 'Evangelical Protestant', 3 = 'Pentecostal', and 4 = 'Mainstream Protestant'). All dummy and continuous variables were grand mean centred (Bickel 2007).

\section{Analysis}

Respondents were not randomly distributed, but grouped into congregations that varied considerably in their migrant profiles. Multi-level regression (Bickel 2007, Snijders and Bosker 1999) allowed for this grouping effect and enabled cross-level interactions to be tested. Analysis was in three stages. The first stage examined the relationship of bridging to bonding using correlation and regression. In the second stage we fitted multi-level models for bonding and bridging separately, testing the interactions of duration and migrant status at the individual level. In the final stage we added contextual-level variables and tested the crosslevel interaction of migrant status and congregation culture. There were too few ABOAP in MonoAsian congregations to test the interaction for this category, but sufficient people of both migrant statuses in MonoAnglo congregations to test them against the rest of the sample. To interpret interactions, we generated estimated marginal means from the fitted models and 
used graphical analysis to display the effects of duration and different congregational cultures on bonding and bridging scores.

\section{Results}

The bonding and bridging scales had Cronbach's alpha reliabilities of .70 and .61 respectively (Tables 2 and 3). Although .61 is slightly below the .65 level of reliability usually considered adequate for summated scales (DeVellis 2003), the coefficient may have been artificially low because the bridging scale relied on dichotomous variables and because activity in one area may have reduced the chances of activity in other areas if time was limited. For bonding, high scores were more frequent for ABOAP than for FGAM in all cases. Bridging items were much less likely to be endorsed generally, but were more often endorsed by ABOAP, except for lending money outside the family and caring for someone who was sick, where there was no difference.

[Tables 1 and 2 about here]

Tests of hypotheses are related to the multilevel models for bonding (Table 4) and bridging (Table 5), and graphical analysis of means (Figures 1-3).

\section{H1.1: Levels of bonding and bridging are positively correlated at both individual and congregational level}

Overall there were significant positive correlations between bridging and bonding scores at both individual level $(r=.34, d f=61,384, p<.001)$ and using mean congregation scores $(r=$ $.39, d f=2133, p<.001)$. The relationship was curvilinear such that individuals with high bonding scores had relatively higher bridging scores than those with low bonding scores (Figure 1).

[Figure 1 about here]

H1.2: FGAM have lower levels of bridging ties, relative to bonding ties, compared with АВOAP

Figure 1 shows that FGAM had lower bridging scores, at any given bonding score, than did ABOAP, supporting H1.2. The difference between migrants and others was most evident 
among those with low bonding scores, and decreased (but was still present) among congregants with the highest bonding scores.

H2.1: For those who have just joined a congregation, FGAM will have similar levels of bonding ties, but lower levels of bridging ties, compared to $A B O A P$

Among those who had been coming for less than a year, FGAM had significantly lower bonding than did ABOAP (Figure 2a), which was not expected from our hypothesis. They did, however have lower levels of bridging ties (Figure 2b), which was predicted by H2.1.

[Figure 2 about here]

H2.2: Once they join a congregation, FGAM develop bonding ties at the same rate as ABOAP, but they develop bridging ties more rapidly because they benefit more from congregational networks for developing such ties

For bonding scores there was no significant interaction between migrant status and duration (Table 4, Model 1), suggesting both groups show similar associations with duration. In both groups there was a marked difference between the $<1$ and 1-2 year groups, with less difference between groups with durations over five years (Figure 2a). For bridging scores there was a significant interaction between duration and migrant status (Table 5, Model 1). For ABOAP, bridging scores increased across the first three duration groups, but showed but little change thereafter, whereas with FGAM there were small incremental increases across all duration levels (Figure 2b). This meant that, over all six levels, duration had a greater effect on bridging among FGAM than among ABOAP, supporting H2.2.

[Tables 4 and 5 about here]

H3.1: FGAM in MonoAsian or Multicultural congregations will have more bonding ties than those in MonoAnglo congregations

For FGAM, bonding scores were significantly lower in MonoAnglo congregations than in MonoAsian and Multicultural congregations (Figure 3a). H3.1 therefore seems to be supported. The comparable results for the 'control' group of ABOAP were in the opposite direction, with bonding capital highest in MonoAnglo and Multicultural congregations and lowest in MonoAsian congregations, though there were too few ABOAP in MonoAsian congregations to test this fully. 
[Figure 3 about here]

\section{H3.2: FGAM in MonoAnglo congregations will have more bridging ties than those other congregations}

Across the whole sample, bridging scores were not significantly higher in MonoAnglo congregations compared with others (Table 5, Model 2), mainly because there was no difference between MonoAnglo and Multicultural congregations in ABOAP (Figure 3b). However there was a significant interaction with migrant status and congregational culture, and FGAM had higher bridging scores in MonoAnglo than in MonoAsian congregations.

\section{Discussion}

This cross-sectional study of 61386 Protestant churchgoers has examined the levels of bonding and bridging social ties among first generation Asian migrants and compared them with those among a control group of Australians born of Australian parents attending a sample of 2135 churches. The results suggest that congregations may promote both bonding and bridging ties, and that the relationships between social ties and duration in the congregation and congregational culture show significant variation between migrants and non-migrants.

Bonding items were much more likely to be endorsed than bridging items. Bridging ties were measured in relation to both outward-orientated church-based activities and activities unconnected to church, but church attenders may have had other routes to developing out-group contacts which were not measured in the survey. It is perhaps not surprising that churches are good at creating bonding ties because care for fellow Christians is at the heart of Christian beliefs, and many church activities are geared to fostering in-group relationships within congregational life. The correlation between bridging and bonding scores, and the positive relationship between duration and bridging ties suggests that congregations can generate social ties beyond their immediate network. The questionnaire did not ask migrants how long they had lived in Australia, and this may have allowed us to separate out the specific effect of duration in congregation from the more general effect of duration in the country (though the two may be closely related). The 2011 NCLS did not have items that specifically asked if bridging activity was a direct result of relationships developed in the congregation, but our results are consistent with this possibility.

\section{Migrant status and social ties}


FGAM had lower bridging ties relative to their level of bonding ties compared to ABOAP. This was true at all levels of bonding ties, but less so where migrants had very high levels of bonding ties. The reasons for this are unclear, and more detailed work on smaller samples is needed to investigate why this is so. The findings here are consistent with the idea that migrants are more reliant on their congregation for developing bridging ties than are nonmigrants, though establishing external network contacts through the congregation is more difficult for migrants, even when they have been in the same congregation for many years.

FGAM had lower average levels of both bonding and bridging than did ABOAP, even after controlling for their different socio-demographic profile and attendance behaviour. This is in line with the lower levels of social capital of non-English speaking congregants in the 2001 NCLS survey (Leonard and Bellamy 2010). This study extends our understanding by showing that this is largely because migrants start with lower levels of both bonding and bridging ties when they arrive in a congregation. Bonding scores tended to develop most rapidly in the first few years after arrival, after which the rate slowed down, especially among FGAM. For FGAM, bridging scores increased slowly but did not seem to plateau, unlike ABOAP. Although congregations do not seem to entirely overcome the inherently lower levels of social ties among Asian migrants, the positive effect of duration suggests than being part of a church may promote the growth of social ties, and therefore perhaps social capital, among those who stay. For migrants this could enhance their integration both by bonding with native-born Australians who are part of their congregation, and by gradually strengthening bridging networks beyond the congregation.

\section{Homophily and social ties}

For bonding ties, the cross-level interaction of congregational culture and migrant status was in the direction predicted by homophily. FGAM had higher levels in Multicultural or MonoAsian congregations than in MonoAnglo congregations. The reverse may have been true for ABOAP, but the numbers in MonoAsian congregations were too low to be sure. The effects of homogeneity on bonding scores were relatively small, but might reflect an underlying difficulty for migrants integrating into predominately non-migrant congregations. This would increase pressure to form separate migrant congregations, either in the same church or in another building. Crucially, FGAM in MonoAnglo congregations had slightly higher bridging scores than those in Multicultural or MonoAsian congregations. The effect was again small but points to the possibility that the blurring of ethnic boundaries in MonoAnglo congregations may be enable Christian FGAM to develop more social ties into 
Australian culture beyond their churches than those who mix primarily with their own ethnic group. Although this does not necessarily mean they are using those ties to develop social capital, it at least suggests they may be better placed to do so.

\section{Conclusions}

This study is based on data collected from a large number of churchgoers from a reasonably representative sample of Protestant congregations. It has the advantage of generalisability, but it suffers from the usual limitations of cross-sectional studies. We cannot tell for certain if the changes with duration were due to individuals developing more ties (as we suggest), or because those with low bonding do not persist in congregations. In may be that both forces are at work, and only longitudinal studies (likely to be on much smaller samples) could answer this for certain. The items in our bonding and bridging scales are typical for large scale surveys that employ proximal measures of the actual networks that social capital theory posits. Although we have used a range of different measures to try and capture different ways in which an individual might bond or bridge, more work is needed to improve the assessment of social ties and social capital in such large-scale surveys. In particular, items relating to how far contacts made through church (rather than ties unconnected with church) have led to migrants accessing the resources associated with social capital would be useful measures of bridging in this context.

Overall, this study provides some evidence that Protestant congregations in Australia can help Asian migrants generate both bonding and bridging networks, and this implies they would be helped to integrate into society. A key finding has been that first generation Asian migrants who belonged to predominantly Anglo congregations found it harder to bond but easier to bridge than their counterparts in Multiracial or MonoAsian congregations. The disadvantage of such large scale studies is that it is difficult to interpret the findings in terms of deciding how exactly congregations foster social integration. Studies that investigate more directly integration among migrants in churches might target both homogenous migrant and mixed congregations, and use qualitative techniques to give a more focused picture of how particular individuals use churches to overcome the barriers of migration. Our study has shown that such detailed work is worthwhile because evidence from a large sample shows that churches do seem to have an influence on the development of social ties among firstgeneration Asian migrants. 
Table 1 Profile of participants.

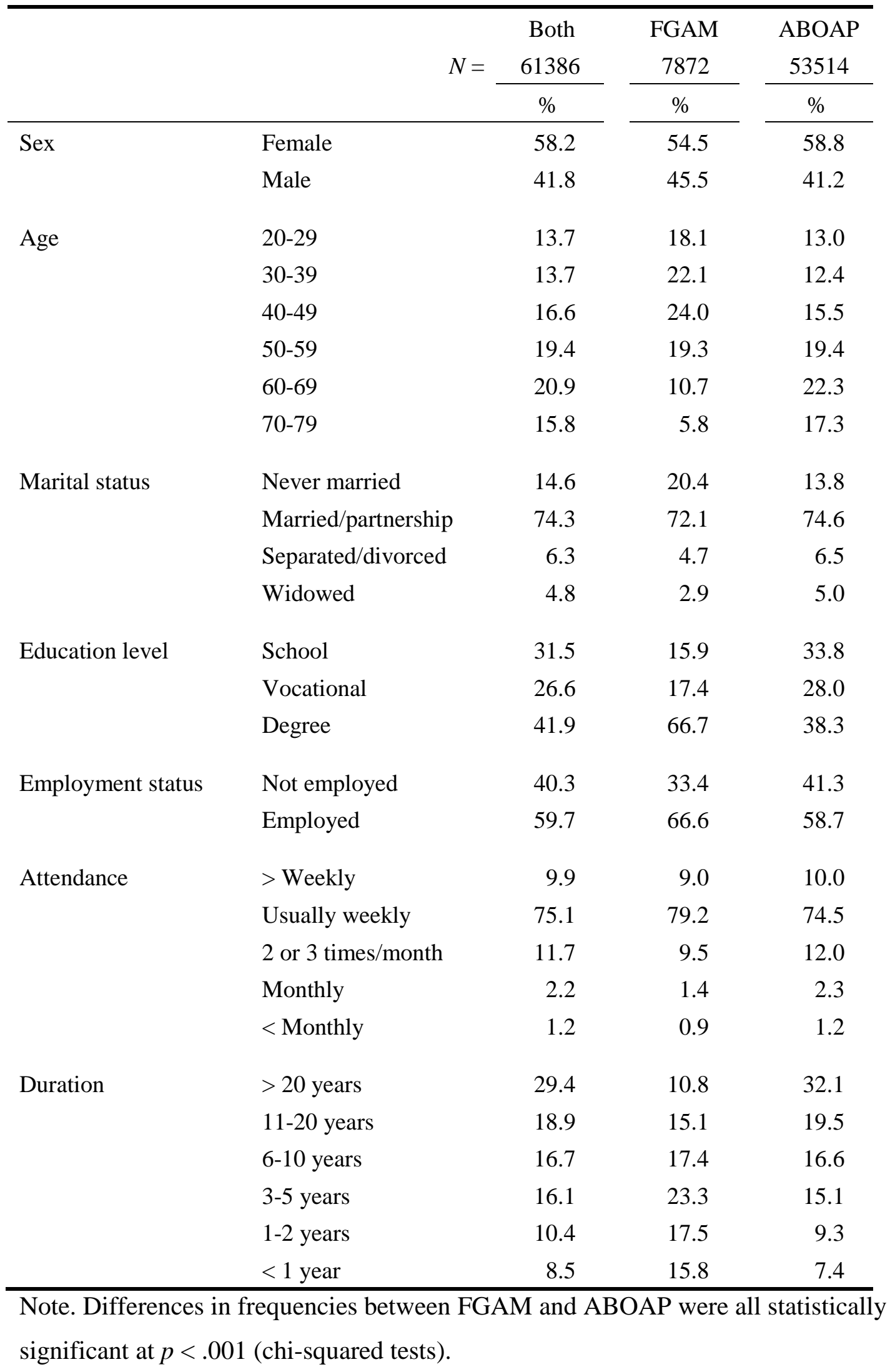


Table 2 Items in the bonding scale.

\begin{tabular}{|c|c|c|c|c|c|c|c|c|c|}
\hline & \multicolumn{3}{|c|}{ Both } & \multicolumn{3}{|c|}{ FGAM } & \multicolumn{3}{|c|}{ ABOAP } \\
\hline$N=$ & \multicolumn{3}{|c|}{61386} & \multicolumn{3}{|c|}{7872} & \multicolumn{3}{|c|}{53514} \\
\hline Score: & 0 & 1 & 2 & 0 & 1 & 2 & 0 & 1 & 2 \\
\hline & $\%$ & $\%$ & $\%$ & $\%$ & $\%$ & $\%$ & $\%$ & $\%$ & $\%$ \\
\hline Congregation activities & 27.9 & 51.6 & 20.5 & 32.6 & 50.9 & 16.5 & 27.2 & 51.7 & 21.1 \\
\hline Congregational belonging & 9.3 & 9.6 & 81.1 & 15.0 & 8.4 & 76.6 & 8.5 & 9.8 & 81.8 \\
\hline Denominational belonging & 7.8 & 12.9 & 79.3 & 6.1 & 17.4 & 76.6 & 8.1 & 12.2 & 79.7 \\
\hline Making friends & 5.1 & 12.1 & 82.8 & 5.2 & 17.8 & 77.0 & 5.1 & 11.2 & 83.7 \\
\hline Financial commitment & 22.0 & 19.9 & 58.1 & 31.3 & 18.7 & 50.0 & 20.6 & 20.0 & 59.3 \\
\hline Congregational roles & 35.5 & 31.5 & 33.0 & 49.6 & 31.2 & 19.2 & 33.4 & 31.6 & 35.0 \\
\hline Gifts encouraged by leadership & 20.7 & 56.4 & 22.9 & 35.5 & 45.0 & 19.5 & 18.5 & 58.1 & 23.4 \\
\hline Mean $=$ & 18.3 & 27.7 & 54.0 & 25.0 & 27.1 & 47.9 & 17.3 & 27.8 & 54.9 \\
\hline
\end{tabular}

Note. For scoring, see text. Differences in frequency between FGAM and ABOAP were tested by chi-squared tests with $2 d f$, and all were significant at $p<.001$. Cronbach's alpha for scale $=.70$. 
Table 3 Items in the bridging scale.

\begin{tabular}{|c|c|c|c|c|c|c|c|}
\hline & \multicolumn{2}{|c|}{$\begin{array}{c}\text { Both } \\
61386\end{array}$} & \multicolumn{2}{|c|}{$\begin{array}{c}\text { FGAM } \\
7872\end{array}$} & \multicolumn{2}{|c|}{$\begin{array}{c}\text { ABOAP } \\
53514\end{array}$} & \\
\hline & No & Yes & No & Yes & No & Yes & \\
\hline & $\%$ & $\%$ & $\%$ & $\%$ & $\%$ & $\%$ & \\
\hline \multicolumn{8}{|l|}{ Church activity: } \\
\hline Community service & 71.3 & 28.7 & 79.6 & 20.4 & 70.1 & 29.9 & $* * *$ \\
\hline Congregational outreach & 72.6 & 27.4 & 76.3 & 23.7 & 72.0 & 28.0 & $* * *$ \\
\hline \multicolumn{8}{|l|}{ Personal activity: } \\
\hline Lent money outside family & 73.2 & 26.8 & 73.1 & 26.9 & 73.3 & 26.7 & NS \\
\hline Cared from someone sick & 69.0 & 31.0 & 68.8 & 31.2 & 69.0 & 31.0 & NS \\
\hline Helped through crisis & 51.1 & 48.9 & 59.0 & 41.0 & 49.9 & 50.1 & $* * *$ \\
\hline Visited in hospital & 43.4 & 56.6 & 61.8 & 38.2 & 40.7 & 59.3 & $* * *$ \\
\hline Gave possessions & 54.9 & 45.1 & 58.4 & 41.6 & 54.4 & 45.6 & $* * *$ \\
\hline Tried to stop substance abuse & 86.2 & 13.8 & 90.8 & 9.2 & 85.6 & 14.4 & *** \\
\hline Donated money & 16.4 & 83.6 & 32.6 & 67.4 & 14.1 & 85.9 & *** \\
\hline Contacted parliamentarian & 78.3 & 21.7 & 92.6 & 7.4 & 76.2 & 23.8 & *** \\
\hline \multicolumn{8}{|l|}{ External group activity: } \\
\hline Community service group & 74.9 & 25.1 & 82.4 & 17.6 & 73.7 & 26.3 & $* * *$ \\
\hline Social action group & 92.7 & 7.3 & 95.3 & 4.7 & 92.3 & 7.7 & $* * *$ \\
\hline School/youth groups & 88.8 & 11.2 & 93.4 & 6.6 & 88.2 & 11.8 & $* * *$ \\
\hline Mean $=$ & 67.1 & 32.9 & 74.2 & 25.8 & 66.1 & 33.9 & \\
\hline
\end{tabular}

Note. Items were scored zero for 'no' and one for 'yes'. Differences in frequency between FGAM and ABOAP were tested by chi-squared tests with $1 d f:{ }^{* * *}=p<.001$, NS $=$ Not Significant. Cronbach's alpha for scale $=.61$. 
Table 4 Individual and congregation-level predictors of bonding scores.

\begin{tabular}{|c|c|c|c|c|}
\hline Parameter & & Null Model & Model 1 & Model 2 \\
\hline & & Estimate $(S E)$ & Estimate $(S E)$ & Estimate $(S E)$ \\
\hline Intercept & & $9.599(0.018)^{* * *}$ & $7.522(0.065)^{* * *}$ & $7.620(0.076)^{* * *}$ \\
\hline $\operatorname{Sex}^{\mathrm{a}}$ & female & & $-0.161(0.021)^{* * *}$ & $-0.160(0.020)^{* * *}$ \\
\hline Age & & & $-0.002(0.001)^{*}$ & $-0.002(0.001)^{*}$ \\
\hline Single & & & $-0.040(0.058) \mathrm{NS}$ & $-0.028(0.058) \mathrm{NS}$ \\
\hline Married/partnership ${ }^{\text {a }}$ & & & $0.208(0.049)^{* * *}$ & $0.213(0.048)^{* * *}$ \\
\hline Divorced/separated ${ }^{\text {a }}$ & & & $-0.295(0.061)^{* * *}$ & $-0.301(0.061)^{* * *}$ \\
\hline Educated to school level $^{\mathrm{a}}$ & & & $-0.307(0.027)^{* * *}$ & $-0.314(0.027)^{* * *}$ \\
\hline Educated to degree level $^{\mathrm{a}}$ & & & $0.144(0.025)^{* * *}$ & $0.157(0.025)^{* * *}$ \\
\hline Employed $^{\mathrm{a}}$ & & & $0.144(0.023)^{* * *}$ & $0.140(0.023)^{* * *}$ \\
\hline Attendance & & & $1.759(0.016)^{* * *}$ & $1.757(0.016)^{* * *}$ \\
\hline \multirow[t]{5}{*}{ Duration (ref = < 1 year) } & $>20$ & & $2.690(0.045)^{* * *}$ & $2.693(0.045)^{* * *}$ \\
\hline & $11-20$ & & $2.458(0.047)^{* * *}$ & $2.464(0.046)^{* * *}$ \\
\hline & $6-10$ & & $2.308(0.047)^{* * *}$ & $2.313(0.047)^{* * *}$ \\
\hline & 3-5 & & $1.922(0.048)^{* * *}$ & $1.923(0.048)^{* * *}$ \\
\hline & $1-2$ & & $1.300(0.052)^{* * *}$ & $1.300(0.052)^{* * *}$ \\
\hline Migrant status $^{a}($ ref $=$ ABOAP $)$ & FGAM & & $-0.869(0.081)^{* * *}$ & $-0.810(0.087)^{* * *}$ \\
\hline Migrant $\mathrm{x}$ Duration ${ }^{\mathrm{b}}$ & & & $F=1.374 \mathrm{NS}$ & $F=1.403 \mathrm{NS}$ \\
\hline Tradition & Other Protestant & & & $0.228(0.071)^{* * *}$ \\
\hline \multirow[t]{2}{*}{ (ref = Mainstream Prot.) } & Evangelical & & & $-0.092(0.036)^{*}$ \\
\hline & Pentecostal & & & $0.360(0.052)^{* * *}$ \\
\hline Size (x 100) & & & & $-0.233(0.018)^{* * *}$ \\
\hline MonoAnglo congregation $^{\mathrm{a}}$ & & & & $-0.106(0.042)^{*}$ \\
\hline Migrant x MonoAnglo & & & & $-0.141(0.071)^{*}$ \\
\hline -2 Restricted Log Likelihood & & 301827 & 283967 & 283765 \\
\hline Number of parameters & & 3 & 23 & 29 \\
\hline Residual & & $7.815(0.045)^{* * *}$ & $5.830(0.034)^{* * *}$ & $5.832(0.034)^{* * *}$ \\
\hline Intercept [subject = church] & & $0.313(0.019)^{* * *}$ & $0.245(0.015)^{* * *}$ & $0.186(0.013)^{* * *}$ \\
\hline ICC & & $3.8 \%$ & $4.0 \%$ & $3.1 \%$ \\
\hline
\end{tabular}


Note. Subject (grouping) variable = church. ICC = Intraclass Correlation Coefficient for churches. ABOAP = Australian born of Australian parents; FGAM = first generation Asian migrant. ${ }^{\mathrm{a}}$ These are dummy variables. ${ }^{\mathrm{b}}$ Parameter estimates for the Migrant $\mathrm{x}$ Duration interaction are not given as these are difficult to interpret; significance is based on the $F$ ratio for the overall fixed effect. $\quad{ }^{*}=p<.05 ;{ }^{* *}=p<.01 ;{ }^{* * *}=p<.001$, NS $=$ not significant. 
Table 5 Individual and congregation-level predictors of bridging scores.

\begin{tabular}{|c|c|c|c|c|}
\hline Parameter & & Null Model & Model 1 & Model 2 \\
\hline & & Estimate $(S E)$ & Estimate $(S E)$ & Estimate $(S E)$ \\
\hline Intercept & & $4.325(0.015)^{* * *}$ & $4.195(0.058)^{* * *}$ & $4.092(0.067)^{* * *}$ \\
\hline Sex ${ }^{a}$ & female & & $-0.557(0.018)^{* * *}$ & $-0.556(0.018)^{* * *}$ \\
\hline Age & & & $0.003(0.001)^{* * *}$ & $0.003(0.001)^{* * *}$ \\
\hline Single ${ }^{\mathrm{a}}$ & & & $-0.182(0.052)^{* * *}$ & $-0.172(0.052)^{* * *}$ \\
\hline Married/partnership ${ }^{\text {a }}$ & & & $0.052(0.044) \mathrm{NS}$ & $0.049(0.044) \mathrm{NS}$ \\
\hline Divorced/separated ${ }^{\text {a }}$ & & & $0.098(0.055) \mathrm{NS}$ & $0.086(0.055) \mathrm{NS}$ \\
\hline Educated to school level ${ }^{\mathrm{a}}$ & & & $-0.516(0.024)^{* * *}$ & $-0.519(0.024)^{* * *}$ \\
\hline Educated to degree level $^{\mathrm{a}}$ & & & $0.294(0.023)^{* * *}$ & $0.312(0.023)^{* * *}$ \\
\hline Employed $^{\mathrm{a}}$ & & & $0.202(0.021)^{* * *}$ & $0.198(0.021)^{* * *}$ \\
\hline Attendance & & & $0.523(0.014)^{* * *}$ & $0.514(0.014)^{* * *}$ \\
\hline \multirow[t]{5}{*}{ Duration (ref = < 1 year) } & $>20$ & & $0.477(0.040)^{* * *}$ & $0.491(0.040)^{* * *}$ \\
\hline & $11-20$ & & $0.447(0.042)^{* * *}$ & $0.455(0.042)^{* * *}$ \\
\hline & $6-10$ & & $0.446(0.042)^{* * *}$ & $0.452(0.042)^{* * *}$ \\
\hline & $3-5$ & & $0.429(0.043)^{* * *}$ & $0.433(0.043)^{* * *}$ \\
\hline & $1-2$ & & $0.156(0.047)^{* * *}$ & $0.160(0.047)^{* * *}$ \\
\hline Migrant status $^{\mathrm{a}}(\mathrm{ref}=\mathrm{ABOAP})$ & FGAM & & $-1.162(0.072)^{* * *}$ & $-1.220(0.078)^{* * *}$ \\
\hline Migrant x Duration ${ }^{a}$ & & & $F=11.306^{* * *}$ & $F=10.476^{* * *}$ \\
\hline Tradition & Other Protestant & & & $0.144(0.059)^{*}$ \\
\hline \multirow[t]{2}{*}{ (ref = Mainstream Prot.) } & Evangelical & & & $0.082(0.030)^{* *}$ \\
\hline & Pentecostal & & & $0.374(0.043)^{* * *}$ \\
\hline Size (x 100) & & & & $-0.078(0.014)^{* * *}$ \\
\hline MonoAnglo congregation ${ }^{a}$ & & & & $0.057(0.035) \mathrm{NS}$ \\
\hline Migrant x MonoAnglo & & & & $0.184(0.064)^{* *}$ \\
\hline -2 Restricted Log Likelihood & & 275335 & 270531 & 270457 \\
\hline Number of parameters & & 3 & 23 & 29 \\
\hline Residual & & $5.078(0.029)^{* * *}$ & $4.713(0.027)^{* * *}$ & $4.713(0.027)^{* * *}$ \\
\hline Intercept [subject = church] & & $0.198(0.013)^{* * *}$ & $0.127(0.010)^{* * *}$ & $0.109(0.009)^{* * *}$ \\
\hline ICC & & $3.8 \%$ & $2.6 \%$ & $2.3 \%$ \\
\hline
\end{tabular}


Note. For explanation, see Table 4. 
Figure 1 Relationship of bridging to bonding scores for first generation Asian migrants (open circles) and Australians born of Australian parents (closed triangles). Error bars show 95\% CL.

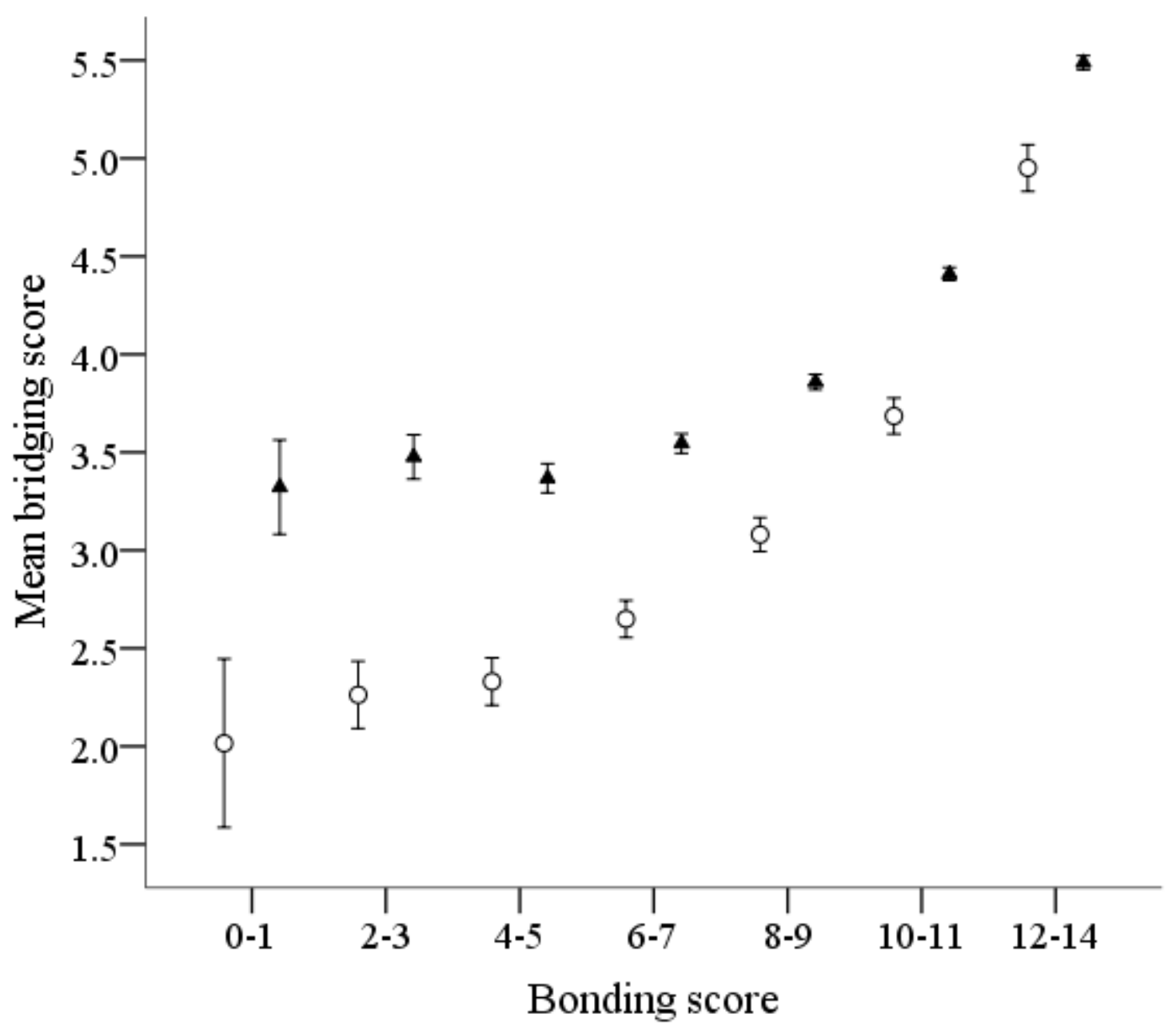


Figure 2 Estimated marginal means ( $\pm 95 \% \mathrm{CI}$ ) of bonding and bridging social capital scores by duration in the congregation for first generation Asian migrants (open circles) and Australians born of Australian parents (closed triangles).
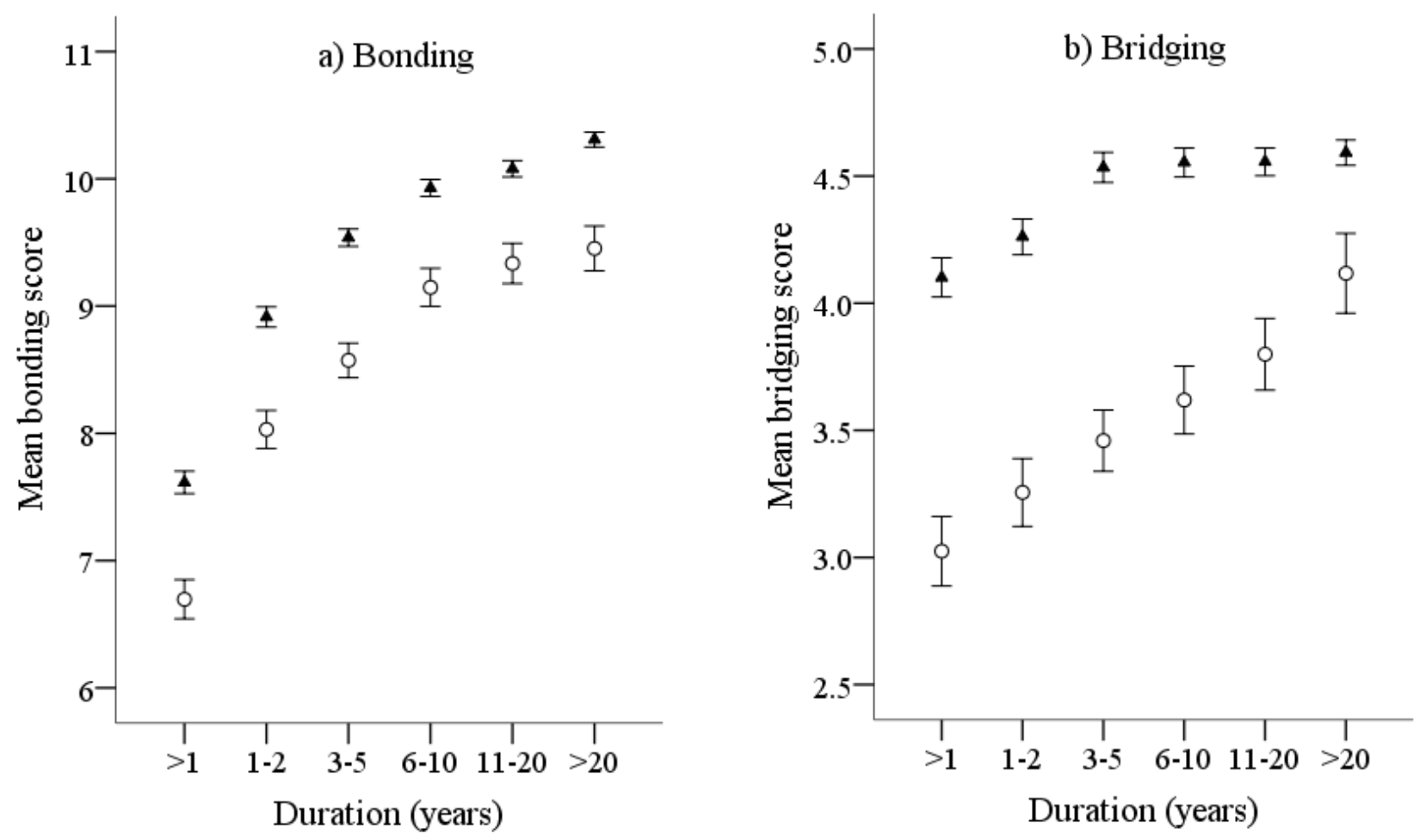
Figure 3 Estimated marginal means $( \pm 95 \%$ CI) of bonding and bridging social capital scores by congregation culture for first generation Asian migrants (open circles) and Australians born of Australian parents (closed triangles). Note: Confidence intervals for ABOAP in MonoAsian congregations are not shown because there were too few in this category.
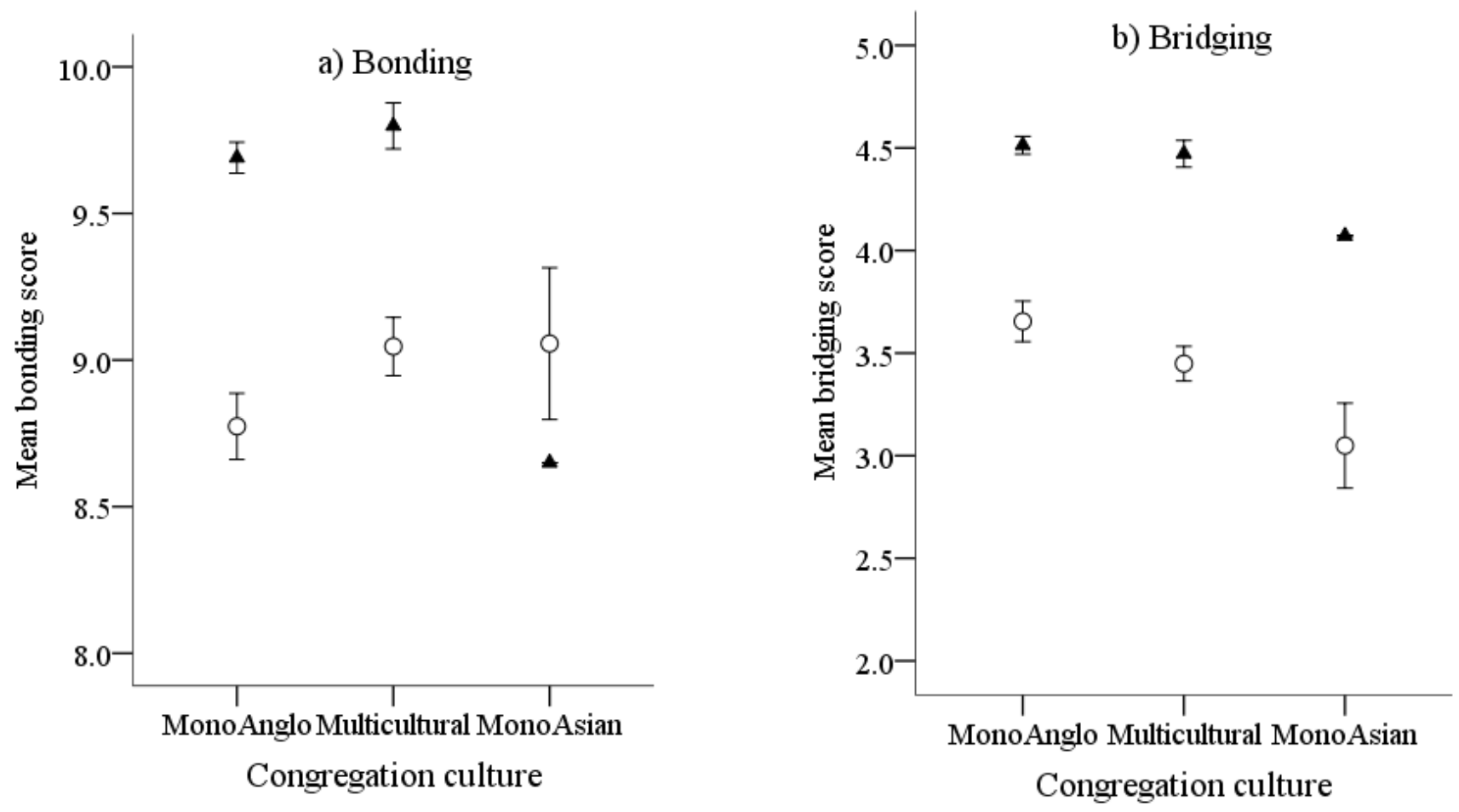


\section{References}

ABS. 2012. Migration. Canberra: Australian Bureau of Statistics.

ABS. 2014. "6250.0 - Characteristics of recent migrants, Australia, Nov 2013." Australian Bureau of Statistics Accessed 12 November 2015.

http://www.abs.gov.au/ausstats/abs@.nsf/mf/6250.0\#.

ABS. 2015. "Australian Bureau of Statistics Census Data." Australian Bureau of Statistics Accessed 21 April 2015. https://www.censusdata.abs.gov.au.

Alba, Richard. 2005. "Bright vs. blurred boundaries: Second-generation assimilation and exclusion in France, Germany, and the United States." Ethnic \& Racial Studies 28 (1):2049. doi: 10.1080/0141987042000280003.

Allen, Ryan. 2010. "The bonding and bridging roles of religious institutions for refugees in a nongateway context." Ethnic \& Racial Studies 33 (6):1049-1068. doi: 10.1080/01419870903118130.

Andrews, Rhys. 2011. "Religious communities, immigration, and social cohesion in rural areas: Evidence from England." Rural Sociology 76 (4):535-561. doi: 10.1111/j.15490831.2011.00057.x.

Ang, Ien. 2003. "From White Australia to Fortress Australia: The anxious nation in the new century." In Legacies of White Australia: Race, culture, and nation, edited by Laksiri Jayasuriya, David Walker and Jan Gothard, 51-69. Crawley, W.A.: University of Western Australia Press.

Baker, Christopher Richard, and Jonathan Miles-Watson. 2010. "Faith and traditional capitals: Defining the public scope of spiritual and religious capital- a literature review." Implicit Religion 13 (1):17-69. doi: 10.1558/imre.v13i1.17.

Beyerlein, Kraig, and John R. Hipp. 2006. "From pews to participation: The effect of congregation activity and context on bridging civic engagement." Social Problems 53 (1):97-117. doi: 10.1525/sp.2006.53.1.97.

Bickel, Robert. 2007. Multilevel analysis for applied research: It's just regression! New York: Guildford Press.

Bjørnskov, Christian, and Kim Sønderskov. 2013. "Is social capital a good concept?" Social Indicators Research 114 (3):1225-1242. doi: 10.1007/s11205-012-0199-1.

Bouma, Gary D. 1995. "The emergence of religious plurality in Australia: A multicultural society." Sociology of Religion 56 (3):285-302. doi: 10.2307/3711824. 
Bouma, Gary D., Rod Ling, and Douglas Pratt. 2014. Religious diversity in Southeast Asia and the Pacific. New York: Springer.

Briggs, Xavier de Souza. 1997. "Social capital and the cities: Advice to change agents." National Civic Review 86 (2):111-117. doi: 10.1002/ncr.4100860204.

Carrington, Kerry, and Neil Marshall. 2008. "Building multicultural social capital in regional Australia." Rural Society 18 (2):117-130. doi: 10.5172/rsj.351.18.2.117.

Cederberg, Maja. 2012. "Migrant networks and beyond: Exploring the value of the notion of social capital for making sense of ethnic inequalities." Acta Sociologica 55 (1):59-72. doi: 10.1177/0001699311427746.

Cheong, P. H., R. Edwards, H. Gouldborne, and J. Solomos. 2007. "Immigration, social cohesion and social capital: A critical review." Critical Social Policy 27 (1):24-49. doi: 10.1177/0261018307072206.

Clyne, Michael G., and James Jupp. 2011. Multiculturalism and integration: A harmonious relationship. Acton, A.C.T.: ANU E Press.

Collins, Jock. 2013. "Multiculturalism and immigrant integration in Australia." Canadian Ethnic Studies Journal 45 (3):133-149. doi: 10.1353/ces.2013.0037.

Connor, Phillip, and Matthias Koenig. 2013. "Bridges and barriers: Religion and immigrant occupational attainment across integration contexts." International Migration Review 47 (1):3-38. doi: 10.1111/imre.12012.

DeVellis, Robert F. 2003. Scale development: Theory and applications. 2nd ed. London: Sage.

DIBP. 2014. The people of Australia: Statistics from the 2011 census. Canberra: Department of Immigration and Border Protection.

DIBP. 2015. "Fact sheet: Key facts about immigration." Department of Immigration and Border Protection Accessed 8th February 2016.

https://www.border.gov.au/about/corporate/information/fact-sheets/02key.

Dougherty, Kevin D. 2003. "How monochromatic is church membership? Racial-ethnic diversity in religious community." Sociology of Religion 64 (1):65-85. doi: 10.2307/3712269.

Duncum, Ian, Nicole Hancock, and Ruth Powell. 2014. Local church engagement with nonEnglish speaking churches, NCLS Research Fact Sheet 14009. In NCLS Research Fact Sheet. Adelaide: Mirrabooka Press.

Emerson, Michael O., and Karen Chai Kim. 2003. "Multiracial congregations: An analysis of their development and a typology." Journal for the Scientific Study of Religion 42 (2):217-227. doi: 10.1111/1468-5906.00174. 
Emerson, Michael O., and Christian Smith. 2000. Divided by faith: Evangelical religion and the problem of race in America. New York: Oxford University Press.

Esser, Harmut. 2008. "The two meanings of social capital." In The handbook of social capital, edited by Dario Castiglione, Jan W Van Deth and Guglielmo Wolleb, 22-49. Oxford: Oxford University Press.

Field, John. 2008. Social capital. 2nd ed. London: Routledge.

Foner, Nancy, and Richard Alba. 2008. "Immigrant religion in the U.S. and Western Europe: Bridge or barrier to inclusion?" International Migration Review 42 (2):360-392. doi: 10.1111/j.1747-7379.2008.00128.x.

Foroutan, Yaghoob. 2008. "Gender, religion and work: Comparative analysis of South Asian migrants." Fieldwork in Religion 3 (1):29-50. doi: io.i558/flel.v3ii.29.

Gordon, Milton M. 1964. Assimilation in American life: The role of race, religion, and national origins. New York: Oxford University Press. Book.

Granberry, Phillip J. 2014. "More social than capital: Social capital accumulation through social network exchange among legal and unauthorized Mexican migrants." The Social Science Journal 51 (4):590-597. doi: 10.1016/j.soscij.2014.09.002.

Granovetter, Mark S. 1973. "The strength of weak ties." American Journal of Sociology 78 (6):1360-1380. doi: 10.1086/225469.

Granovetter, Mark S. 1983. "The strength of weak ties: A network theory revisited." Sociological Theory 1 (1):201-233. doi: 10.2307/202051.

Greeley, Andrew M. 1997. "Coleman revisited: Religious structures as a source of social capital." American Behavioral Scientist 40 (5):587-594. doi: 10.1177/0002764297040005005

Handlin, Oscar. 1951. The uprooted: The epic story of the great migrations that made the American people. New York: Grosset \& Dunlap. Book.

Herberg, Will. 1955. Protestant, Catholic, Jew: An essay in American religious sociology. Garden City, NY: Doubleday.

Iosifides, Theodoros, Mari Lavrentiadou, Electra Petracou, and Antonios Kontis. 2007. "Forms of social capital and the incorporation of Albanian immigrants in Greece." Journal of Ethnic \& Migration Studies 33 (8):1343-1361. doi: 10.1080/13691830701614247.

Jacobs, Dirk, and Jean Tillie. 2004. "Introduction: Social capital and political integration of migrants." Journal of Ethnic \& Migration Studies 30 (3):419-427. doi:

10.1080/13691830410001682016. 
Jayasuriya, Laksiri, and Pookong Kee. 1999. The Asianisation of Australia? Some facts about the myths. Carlton South, Vic.: Melbourne University Press.

Jupp, James. 1995. "From 'White Australia' to 'Part of Asia': Recent shifts in Australian immigration policy towards the region." International Migration Review 29 (1):207-228. doi: $10.2307 / 2547002$.

Jupp, James. 2009. "Immigrant settlement, ethnic relations and multiculturalism in Australia." In Nations of immigrants: Australia and the USA compared, edited by John Higley, John Nieuwenhuysen and Stine Neerup, 147-159. Cheltenham, UK: Edward Elgar Publishing.

Lancee, Bram. 2010. "The economic returns of immigrants' bonding and bridging social capital: The case of the Netherlands." International Migration Review 44 (1):202-226. doi: 10.1111/j.1747-7379.2009.00803.x.

Lancee, Bram. 2012. "The economic returns of bonding and bridging social capital for immigrant men in Germany." Ethnic \& Racial Studies 35 (4):664-683. doi: 10.1080/01419870.2011.591405.

Lazersfeld, Paul F., and Robert K. Merton. 1954. "Friendship as social process: A substantive and methodological analysis." In Freedom and control in modern society, edited by M. Berger, 18-66. New York: Van Nostrand.

Leonard, Rosemary, and John Bellamy. 2006. "Volunteering within and beyond the congregation: A survey of volunteering among Christian church attendees." Australian Journal on Volunteering 11 (2):16-24.

Leonard, Rosemary, and John Bellamy. 2010. "The relationship between bonding and bridging social capital among Christian denominations across Australia." Nonprofit Management \& Leadership 20 (4):445-460. doi: 10.1002/nml.20004.

Leonard, Rosemary, and John Bellamy. 2015. "Dimensions of bonding social capital in Christian congregations across Australia." Voluntas 26 (4):1046-1065. doi: 10.1007/s11266-0159582-2.

Ley, David. 2008. "The immigrant church as an urban service hub." Urban Studies 45 (10):20572074. doi: http://usj.sagepub.com/content/by/year.

Lin, Nan. 1999. "Building a network theory of social capital." Connections 22 (1):28-51.

Liu, Mao-Mei. 2013. "Migrant networks and international migration: Testing weak ties." Demography 50 (4):1243-1277. doi: 10.1007/s13524-013-0213-5.

Maliepaard, Mieke, and Karen Phalet. 2012. "Social integration and religious identity expression among Dutch Muslims: The role of minority and majority group contact." Social Psychology Quarterly 75 (2):131-148. doi: 10.1177/0190272511436353. 
McPherson, Miller, Lynn Smith-Lovin, and James M. Cook. 2001. "Birds of a feather: Homophily in social networks." Annual Review of Sociology 27:415-444. doi:

10.1146/annurev.soc.27.1.415.

Missingham, Bruce, Jacqui Dibden, and Chris Cocklin. 2006. "A multicultural countryside? Ethnic minorities in rural Australia." Rural Society 16 (2):131-150. doi:

10.5172/rsj.351.16.2.131.

Moroşanu, Laura. 2016. "Professional bridges: Migrants' ties with natives and occupational advancement." Sociology 50 (2):349-365. doi: 10.1177/0038038514568234.

NCLS. 2013. "First results from 2011 National Church Life Survey." NCLS Australia Accessed 1st April. http://www.ncls.org.au/default.aspx?sitemapid=6988.

Noguera, Caries X. Simo, Benno Herzog, and Jolien Fleerackers. 2013. "Forms of social capital among European retirement migrants in the Valencian Community/Tipos de capital social entre los inmigrantes Europeos retirados en la Comunidad Valenciana." Migraciones Internacionales 7 (1):131-163.

Pepper, Miriam, Sam Sterland, and Ruth Powell. 2015. "Methodological overview of the study of well-being through the Australian National Church Life Survey." Mental Health, Religion \& Culture 18 (1):8-19. doi: 10.1080/13674676.2015.1009717.

Peschke, Doris. 2009. "The role of religion for the integration of migrants and institutional responses in Europe: Some reflections." The Ecumenical Review 61 (4):367-380. doi: 10.1111/j.1758-6623.20009.00034.x

Portes, Alejandro. 1998. "Social capital: Its origins and applications in modern sociology." Annual Review of Sociology 24:1-24. doi: 10.1146/annurev.soc.24.1.1.

Putnam, Robert D. 2000. Bowling alone: The collapse and revival of American community. New York: Simon \& Schuster.

Putnam, Robert D., Robert Leonardi, and Raffaella Y. Nonetti. 1994. Making democracy work: Civic traditions in modern Italy. Princeton, NJ: Princeton University Press. Book.

Robbins, Mandy, Leslie J. Francis, and Ruth Powell. 2012. "Congregational bonding social capital and psychological type: An empirical enquiry among Australian churchgoers." Mental Health, Religion \& Culture 15 (10):1009-1022. doi: 10.1080/13674676.2012.676264.

Ryan, Louise. 2011. "Migrants' social networks and weak ties: Accessing resources and constructing relationships post-migration." The Sociological Review 59 (4):707-724. doi: 10.1111/j.1467-954X.2011.02030.x. 
Schwadel, Philip. 2005. "Individual, congregational, and denominational effects on church members' civic participation." Journal for the Scientific Study of Religion 44 (2):159-171. doi: 10.1111/j.1468-5906.2005.00273.x.

Smidt, Corwin, ed. 2003. Religion as social capital. Waco, Tx: Baylor University Press.

Smidt, Corwin, John Green, James Guth, and Lyman A. Kellstedt. 2003. "Religious involvement, social capital and political engagement: A comparison of the United States and Canada." In Religion as social capital, edited by Corwin Smidt, 153-170. Waco, TX: Baylor University Press.

Snijders, Tom A. B. 1999. "Prologue to the measurement of social capital." La Revue Tocqueville 20 (01):27-44.

Snijders, Tom A. B., and Roel J. Bosker. 1999. Multilevel analysis: An introduction to basic and advanced multilevel modeling. London: Sage.

Svendsen, Gunnar. 2006. "Studying social capital in situ: A qualitative approach." Theory \& Society 35 (1):39-70. doi: 10.1007/s11186-006-6780-3.

Watson, Sophie. 2009. "Performing religion: Migrants, the church and belonging in Marrickville, Sydney." Culture and Religion 10 (3):317-338. doi: 10.1080/14755610903287716.

Weller, Paul. 2005. "Religions and social capital. These on religion(s), state(s), and society(ies): with particular reference to the United Kingdom and the European Union." Journal of International Migration \& Integration 6 (2):271-289. doi: 10.1007/s12134-005-1014-5.

Wilson, John, and Thomas Janoski. 1995. "The contribution of religion to volunteer work." Sociology of Religion 56 (2):137-152. doi: 10.2307/3711760. 